\title{
COMPARATIVE PALEOECOLOGY OF PALEOGENE AND NEOGENE MAMMALIAN FAUNAS: GUILD STRUCTURE AND DIVERSITY
}

GUNNELL*, Gregg F., GINGERICH, Philip D., Museum of Paleontology, Univ. of Michigan, Ann Arbor, MI, 48109; MORGAN, Michele E., Dept. of Anthropology, Harvard Univ., Cambridge, MA, 02138; MAAS, Mary, Dept. of Biological Anthropology and Anatomy, Box 3170, Duke Univ., Durham, NC, 27710.

We examined guild structure and diversity in the mammalian biota of the Paleogene of Wyoming and Montana and the Neogene of Pakistan. Trophic structure was measured as frequency of generic diversity in each of the following trophic categories: insectivore, omnivore, frugivore, herbivore, and carnivore. Trophic categories were inferred from dental morphology.

Results are summarized below (see graphs). In Wyoming/Montana, the Paleocene is dominated by herbivores (from the orders Condylarthra, Multituberculata, and Pantodonta) and insectivores ("Proteutheria" and Proprimates). In the early Eocene, herbivores (Perissodactyla, Artiodactyla, and Rodentia), carnivores (Carnivora, Creodonta, and Mesonychia), and insectivores ("Proteutheria," Proprimates, and Primates) dominate. At the beginning of the Eocene, carnivores and insectivores are more diverse than herbivores, but later, herbivores are more diverse. Adapid primates become an important frugivore element in the early Eocene. Herbivores are the most common group throughout the sequence, ranging from $30 \%$ to $75 \%$ of all specimens.

In the Siwaliks, herbivores (from Proboscidea, Rodentia, Perissodactyla, and Artiodactyla) dominate in generic diversity $(70-80 \%)$, with artiodactyls consistently representing about $50 \%$ of herbivore genera. Circa $16 \mathrm{Ma}$, rodents appear and become an important herbivore group. At $14 \mathrm{Ma}$, bovid diversity increases dramatically. Specialized browsers (tragulids, giraffids) and grazers (suids) represent $25 \%$ to $35 \%$ of herbivore diversity throughout the sequence. Carnivores, represented by creodonts and true carnivores, range from 5\% to $20 \%$ of generic diversity in the Siwaliks. At $11 \mathrm{Ma}$, carnivores increase in generic diversity with amphicyonid and hyaenid carnivores dominating the guild. Carnivores and insectivores are never as diverse in the Siwaliks as they are in the early Eocene of North America.
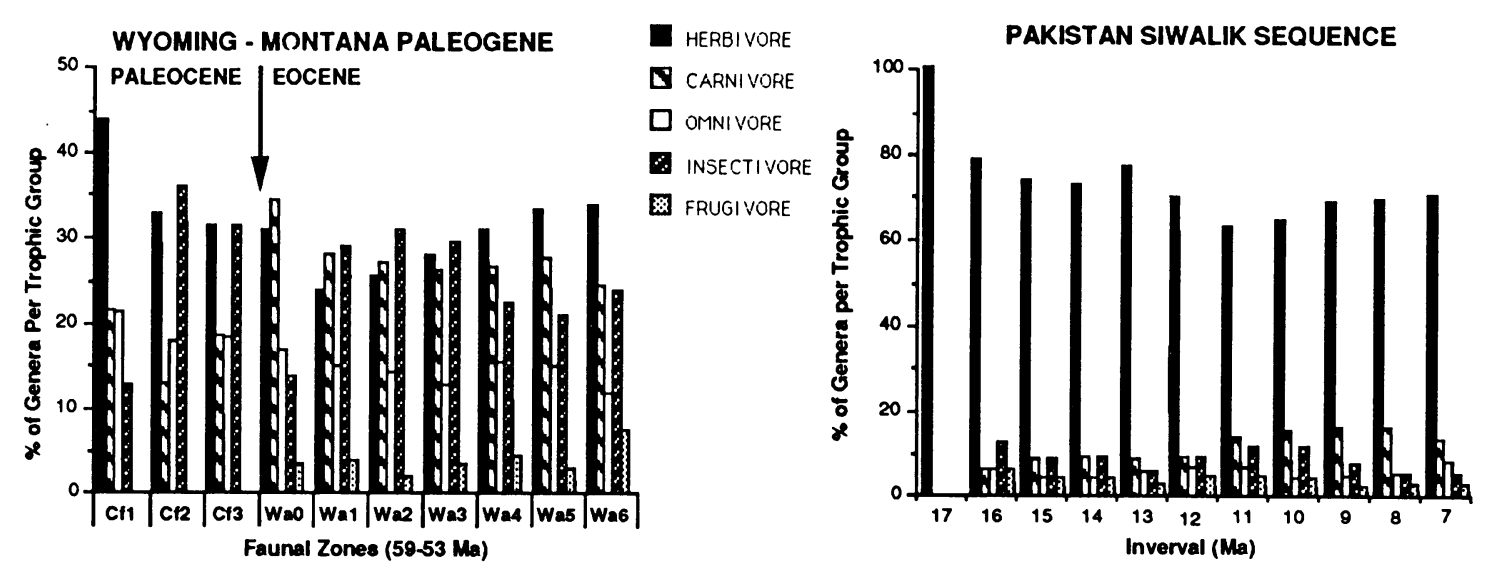